\title{
Sellado de catéteres con gelafundina versus heparina sódica
}

\section{Rubén Sierra Díaz}

Centro de Diálisis Bellavista, Fresenius Medical Care. Sevilla

\section{Resumen}

La mayor parte de los pacientes que actualmente inician diálisis, son de edad avanzada con patologías crónicas y complicaciones vasculares, requiriendo de la utilización de catéteres venosos centrales para la realización de hemodiálisis. Esta realidad de nuestros centros, ha determinado que enfermería tenga que adaptar su trabajo al cuidado de dichos catéteres asegurando poder acceder a un flujo de sangre suficiente para realizar una diálisis eficaz.

Tras un cambio producido en nuestra unidad respecto al sellado de las ramas de los catéteres, pasando de un protocolo tradicional con suero fisiológico y heparina sódica al $5 \%$, a otro constituido por suero fisiológico y gelafundina, se planteó como objeto de estudio realizar una comparación de ambos protocolos valorando aspectos como incidencia de infecciones, disfunciones del catéter por obstrucción e ingresos hospitalarios.

Del estudio comparativo constituido por 1248 sesiones de diálisis de 16 pacientes portadores de catéteres permanente (624 sesiones con cada protocolo) se obtuvo: que no hubo ningún ingreso hospitalario derivado de la disfunción del catéter; que con protocolos diferentes aparecieron infecciones, siendo éstas en su mayoría locales; que tuvieron lugar incidencias relacionadas con el flujo sanguíneo en ambos tipos de protocolos, siendo más frecuente la

Correspondencia: ercoordi@hotmail.com utilización de inversión de ramas en caso de cebado con heparina sódica y necesitándose más uso de protocolo con urokinasa en la fase de cebado con gelafundina.

\section{PALABRAS CLAVE:}

- GELAFUNDINA

- HEPARINA SÓDICA

- CATÉTER VENOSO CENTRAL PERMANENTE

- HEMODIÁLISIS

- ACCESO VASCULAR

\section{Sealing catheters with gelafundin compared to sodium heparin}

\section{Abstract}

Most patients who currently commence dialysis are of advanced age and have chronic diseases and vascular complications, requiring the use of central venous catheters to carry out haemodialysis. This situation in our centres has meant that nursing staff have had to adapt their work to the care of these catheters ensuring access to a blood flow that is sufficient for efficacious dialysis.

After a change in our unit in the sealing of catheter branches, from a traditional protocol with physiological serum and $5 \%$ sodium heparin to another made up of physiological serum and gelafundin, it was suggested that a study be carried out to compare the two protocols, evaluating aspects such as incidence of infections, dysfunctions of the catheter due to obstruction and hospital admissions. 
The following results were obtained from the comparative study carried out over 1248 dialysis sessions of 16 patients with permanent catheters ( 624 sessions with each protocol): there were no admissions to hospital deriving from catheter dysfunction; with different protocols infections appeared, mostly local; there were incidents related to blood flow in both types of protocol, with the use of branch inversion being more frequent when primed with sodium heparin and with greater user of protocol with urokinase in the phase of priming with gelafundin.

\section{KEY WORDS:}

- GELAFUNDIN

- SODIUM HEPARIN

- PERMANENT CENTRAL VENOUS CATHETER

- HAEMODIALYSIS

- VASCULAR ACCESS

\section{Introducción}

Para los pacientes en programa de hemodiálisis, el ser portador de un buen acceso vascular les garantiza la posibilidad de recibir un tratamiento correcto de diálisis, a la vez que disminuye la morbi-mortalidad. La incidencia actual de los pacientes que inician diálisis crónica sigue aumentando en nuestro país, caracterizándose por pacientes añosos, con otras patologías crónicas y con complicaciones vasculares. Esta situación trae consigo la limitación de accesos vasculares para realizar hemodiálisis. Por esta razón, los catéteres venosos centrales son usados frecuentemente como acceso vascular para la hemodiálisis ${ }^{1}$. Así pues tanto catéteres venosos temporales como permanentes constituyen hoy día una realidad en nuestros centros de diálisis siendo la vía de elección del acceso vascular para los pacientes. No debemos olvidar que para gran parte de los pacientes portadores de catéteres suele ser el último acceso vascular tras la imposibilidad de la realización de fístulas arterio-venosas y que para otros puede constituir el acceso vascular de inicio derivado de otras patologías asociadas. Al mismo tiempo el uso de catéteres tanto temporales como permanentes puede traer consigo la aparición de complicaciones como son la bacteriemia, infecciones locales, obstrucción del catéter, etc.
Enfermería ha tenido que adaptar a su trabajo diario una serie de cuidados encaminados al mantenimiento del buen estado de estos accesos vasculares ${ }^{2}$. Uno de los principales cuidados ha ido dirigido a garantizar la permeabilidad de dichos catéteres entre las sesiones, asegurándonos poder acceder a un flujo de sangre suficiente para realizar la hemodiálisis y por tanto conseguir una eficacia dialítica óptima³.

En nuestro centro se cebaban, para el lavado de posibles restos sanguíneos, las ramas de los catéteres una vez finalizada la sesión con la instilación de $20 \mathrm{ml}$ de suero fisiológico, más 2,5 cc de heparina sódica al $5 \%$. Recientemente se produjo un cambio en el sellado, sustituyendo la heparina, por $5 \mathrm{cc}$ de gelafundina que es una solución coloide tipo gelatina procedente de la degradación del colágeno animal, cuyo peso molecular oscila entre 15.000 y 90.000 daltons. Entre las diversas funciones conocidas de los coloides está la de alterar la estabilidad del coágulo de fibrina y por tanto tener cierto efecto fibrinolítico ${ }^{4}$.

Inquietados por el cambio de protocolo y sus posibles consecuencias en nuestros pacientes y sus accesos vasculares, el equipo de enfermería consideró oportuno realizar un estudio comparativo entre ambos protocolos de sellado para poder determinar cual garantizaba una mayor efectividad en la calidad del tratamiento.

\section{Objetivos}

Comparar dos protocolos diferentes de sellados de las ramas de los catéteres en nuestra unidad de hemodiálisis durante seis meses, valorando las diferencias entre la incidencia de infecciones, las disfunciones del catéter por obstrucción, los ingresos hospitalarios y el uso de protocolo de desobstrucción.

\section{Material y método}

Estudio observacional comparativo, realizado durante los meses comprendidos entre julio y diciembre del 2008, en el centro periférico de Bellavista. La muestra estuvo compuesta por 16 pacientes portadores de catéteres permanentes, de los cuales el $43,7 \%$ eran hombres y el $56,3 \%$ mujeres. Consta de dos fases, la primera en la que se recogieron datos de estos pacientes portadores de catéteres permanentes que 
fueron sellados durante 39 sesiones consecutivas con protocolo tradicional de lavado con suero fisiológico y heparina sódica al 5\%. La segunda fase del estudio, se centró en los mismos pacientes portadores de los mismos catéteres y de igual número de sesiones que en la fase anterior, pero con la diferencia de que usaron el nuevo protocolo de sellado de las ramas del catéter con suero fisiológico y gelafundina.

De un total de 19 pacientes portadores de catéteres permanentes que se encontraban en el centro durante el período de estudio quedaron excluidos 2 pacientes por ingreso hospitalario y 1 paciente por cambio de catéter.

Para poder comparar ambos protocolos procedimos a la recogida de los siguientes datos:

- Existencia de infección local y sistémica

- Uso de mupirocina

- Hemocultivos positivos

- Necesidad de utilizar el protocolo de desobstrucción con urokinasa

- Ingreso hospitalario derivado de disfunción de catéter

- Flujo de bomba

- Presión arterial

- Presión venosa

- Volumen acumulado

- Inversión de ramas de catéter

Dichos datos se anotaron por el personal de enfermería en un registro elaborado específicamente para el estudio.

En ambos períodos el protocolo de actuación para el sellado de las ramas de los catéteres fue el mismo:

1.Una vez retornada la sangre tras la finalización de la sesión de hemodiálisis con suero fisiológico, se procede a la desconexión de la rama arterial y colocación de una jeringa de 20 cc de suero fisiológico.

2.Se desconecta la rama venosa y se coloca una jeringa con 20 cc de suero fisiológico.

3.Se procede a la instilación de los 20 cc de suero fisiológico y a la limpieza de las conexiones de ambas ramas con gasas empapadas en clorhexidina al $2 \%$.

4.Se retiran las jeringas de 20 cc y se colocan en su lugar las jeringas cargadas en el primer período del estudio con 2,5 cc de heparina sódica al 5\% y en el segundo período del estudio con $5 \mathrm{cc}$ de gelafundina. A continuación se ceban las ramas del catéter con dichas sustancias.

\section{Resultados}

En el período de estudio se analizaron 1248 sesiones de diálisis (624 sesiones con protocolo de sellado con heparina sódica al 5\% y 624 sesiones con protocolo de sellado con gelafundina) obteniéndose los siguientes resultados:

Respecto al número de ingresos hospitalarios no se produjo ningún ingreso de pacientes provocado por la disfunción del catéter en las fases del estudio mientras que los resultados obtenidos en los datos de Presión Venosa (PV), Presión Arterial (PA), Flujo (Qb) y Volumen Acumulado (V) fueron similares en ambos tipos de protocolos de sellado (tabla1).

\begin{tabular}{|c|c|c|}
\hline & $\begin{array}{c}\text { Fase } 1 \\
\text { Sellado con } \\
\text { Heparina al } \\
5 \%\end{array}$ & $\begin{array}{l}\text { Fase } 2 \\
\text { Sellado con } \\
\text { Gelafundina }\end{array}$ \\
\hline Infección Local (uso de mupirocina) & 7 casos & 4 casos \\
\hline $\begin{array}{l}\text { Infección Sistémica con hemocultivos } \\
\text { positivos (+) }\end{array}$ & 2 casos & 2 casos \\
\hline Protocolo Urokinasa & 3 casos & 5 casos \\
\hline Ramas Invertidas & 22 sesiones & 13 sesiones \\
\hline $\begin{array}{l}\text { Ingreso derivado por disfunción del } \\
\text { Catéter }\end{array}$ & 0 & 0 \\
\hline Media Presión Venosa (PV) & $200 \mathrm{~mm} \mathrm{Hg}$ & $210 \mathrm{~mm} \mathrm{Hg}$ \\
\hline Media Presión Arterial (PA) & $-210 \mathrm{~mm} \mathrm{Hg}$ & $-220 \mathrm{~mm} \mathrm{Hg}$ \\
\hline Media Flujo (Qb) & $315 \mathrm{ml} / \mathrm{min}$ & $310 \mathrm{ml} / \mathrm{min}$ \\
\hline Media Volumen Acumulado (V) & 63 litros & 64,8 litros \\
\hline
\end{tabular}

Tabla 1. Resultados de ambos protocolos

Cabe destacar que del total de las infecciones de nuestra muestra estudiada se observó que predominaron las infecciones locales $(73,33 \%)$ frente a las infecciones sistémicas $(26,67 \%)$; se consideraron infecciones locales aquellas que necesitaron de tratamiento tópico con mupirocina e infecciones sistémicas aquellas que tras hemocultivos periféricos y centrales positivos, requirieron de antibióticos intravenosos. Al comparar ambos tipos de sellados y su incidencia con respecto a 
las infecciones, se verificó un mayor número de infecciones locales en las sesiones que fueron selladas con protocolo de heparina al $5 \%$ (el 63,64\%) mientras que las infecciones sistémicas que se produjeron durante el estudio se repartieron de forma equitativa en los dos protocolos ( 2 casos en cada uno). Así pues, atendiendo al tipo de sellado podemos destacar que se produjeron 9 infecciones en la Fase 1 y 6 en la Fase 2.

En relación a las incidencias producidas en el flujo sanguíneo $\mathrm{Qb}$, destacamos que fue la fase en la que se usó el protocolo de heparina sódica al 5\%, la que más incidencia reflejó (58,14\%). Entre éstas se consideraron los casos en los que se tuvieron que realizar protocolos de desobstrucción con urokinasa y los que se tuvieron que invertir las ramas del catéter durante la sesión para poder realizar la misma. La necesidad de invertir las ramas de los catéteres fue mayor en las sesiones cuyo protocolo de sellado fue con heparina sódica al 5\% (62,86\%), mientras que el uso de urokinasa fue superior en los casos de cebado con gelafundina $(62,5 \%)$.

\section{Discusión}

Nuestra experiencia tras valorar dos protocolos diferentes de sellados para catéteres permanentes, uno utilizando heparina sódica al 5\% y otro gelafundina, nos permite afirmar que en ambas fases de estudio con protocolos diferentes existieron la aparición de infecciones, siendo éstas en su mayoría locales (necesidad de uso tópico de mupirocina) y que fueron las sesiones cuyo sellado se realizó con heparina sódica al $5 \%$ las que más infecciones locales presentaron siendo el número de casos de infecciones sistémicas similar en ambos períodos de estudio por tanto, parece que ambos protocolos no inciden de forma específica en la aparición de infecciones y que las medidas profilácticas para evitar estos eventos deben contemplar otras actuaciones ${ }^{1-3}$.

También nos encontramos con incidencias relacionadas con el flujo sanguíneo en los dos tipos de protocolos, siendo más frecuente la utilización de la inversión de ramas en caso de cebado con heparina sódica y necesitándose más el uso de protocolo con urokinasa en la fase de cebado con gelafundina pero en ambos casos el número de intervenciones fue aceptable. Así mismo los parámetros dialíticos fueron similares en ambas fases, lo que unido al hecho de que no existió ningún ingreso hospitalario causado por disfunción del catéter, nos permite afirmar que no existe ninguna contraindicación específica para utilizar gelofundina en el cebado de las ramas del catéter para su conservación.

\section{Bibliografía}

1. Domingo Cebrián E, Alonso Salamanca J, González Molina $\mathrm{J}$ et al. Catéteres en las Unidades de Hemodiálisis una realidad que no puede ser ignorada. En: Libro de Comunicaciones del XXIX Congreso de la Sociedad Española de Enfermería Nefrológica; Tenerife 2004. Barcelona: HOSPAL; 2004. p. 320321.

2. Tordoir HM J, Miccley V. Recomendaciones Europeas para el Acceso Vascular: Algoritmos Clínicos sobre el Acceso Vascular para Hemodiálisis. EDTNA / ERCA Journal 2003; XXIX (3): 133-139.

3. Polaschegg HD, Sodemann K, Feldmer B. Aumento de la permeabilidad, Seguridad y Eficacia en el Coste de los Catéteres. EDTNA / ERCA Journal 2002; XXVIII (1): 29-33.

4. Abramson N. Plasma expanders and bleeding. Ann Intern Med 1988; 108:307-12. 